\title{
Eosinophil, basophil, and mast cell infiltrates in the bone marrow: crossing the boundaries of diagnosis
}

\author{
Hans-Peter Horny • Karl Sotlar • Peter Valent
}

Received: 6 May 2011 / Accepted: 6 May 2011 / Published online: 28 May 2011

(C) Springer-Verlag 2011

\begin{abstract}
An increase in eosinophils, basophils, and/or mast cells in the bone marrow may pose considerable diagnostic problems for the hematopathologist. In a first step, it is crucial to classify these changes as either being reactive or neoplastic. A slight increase in eosinophils is often seen in reactive states of myeloid hyperplasia while an increase in basophils is usually indicative of a neoplastic hematologic disorder. Regarding mast cells, the presence of compact infiltrates is the major criterion for systemic mastocytosis whereas a diffuse interstitial increase is often encountered in reactive states of mast cell hyperplasia. When a neoplastic disorder is diagnosed, definitive classification depends on immunohistochemical, molecular, and cytogenetic markers. The use of a limited panel of antibodies against basophil-, eosinophil-, and mast cell-related antigens like 2D7, eosinophil major basic protein, tryptase, and CD117 (KIT) is sufficient to identify diffuse or compact infiltrates and to provide semiquantitative analysis of accumulations of neoplastic or reactive cells. We therefore recommend the use of such markers which may increase the value of hematopathologic investigations and thereby are of major help to improve diagnosis and prognostication in these patients.
\end{abstract}

Keywords Basophilic leukemia $\cdot$ Basophils $\cdot$ Bone marrow Eosinophilic leukemia $\cdot$ Eosinophils $\cdot$ Mast cells . Mastocytosis $\cdot$ Myeloproliferative neoplasm with eosinophilia $\cdot$ Systemic mastocytosis

\section{H.-P. Horny $(\triangle)$}

Institute of Pathology,

Ansbach, Germany

e-mail: horny@patho-ansbach.de

K. Sotlar

Institute of Pathology, Ludwig-Maximilians-University,

Munich, Germany

P. Valent

Division of Hematology and Hemostaseology,

Department of Internal Medicine, Medical University of Vienna,

Vienna, Austria

\section{Introduction}

Although constituting only minor hematopoietic cell populations in terms of quantity, an increase of eosinophilic, basophilic, and/or mast cell infiltrates may pose a considerable diagnostic challenge for the hematopathologist during routine workup [1,2]. While a slight diffuse increase in eosinophils is a common finding in reactive bone marrow, an increase in basophils should be regarded as strong evidence for a neoplastic hematological disorder. An increase in mast cells presenting as loosely scattered round well-granulated cells is often seen and can be interpreted as mast cell hyperplasia unless biochemical evidence of mastocytosis is provided, while the detection of at least one compact mast cell infiltrate in the bone marrow (or any other extracutaneous tissue site) is highly suggestive for the diagnosis of systemic mastocytosis [3].

This review includes not only recommendations for the histological and immunohistochemical approach to detect and quantify an increase in eosinophils, basophils, and/or mast cells in the bone marrow but also presents some unusual myeloid neoplasms which, even after extensive immunohistochemical analysis, cannot be posed in any defined category of hematological tumors and therefore have to be regarded as being "crossing the boundaries of diagnosis."

\section{Diagnostic approach}

Eosinophilic granulocytes

Regarding histological sections, eosinophils can best be identified in Giemsa stains by their bright orange red intracytoplasmic granules. The use of immunostains like anti-eosinophil major basic protein for detection of eosino- 
phils is not widely used and therefore cannot be recommended for diagnostic routine workup at present.

Cytological atypia of eosinophils is easily detected in smear preparations of blood and bone marrow comprising hypersegmentation of nuclei, granulation defects of the cytoplasm but also increase in immature forms sometimes exhibiting the so-called mixed granulation with the occurrence of "basophilic granules" intermingled with the specific eosinophilic ones [4]. While immunohistochemical atypia of eosinophils is not known and of no relevance in diagnostic hematopathology, cytochemical aberration with expression of the naphthol-AS-D-chloroacetate esterase is an important feature for separation of acute myeloid leukemia with anomalies of chromosome 16 (formerly termed "AMLFABM4Eo") from other myeloid neoplasms with eosinophilia [5].

\section{Basophilic granulocytes}

Basophils are not detectable in routine histology because their specific metachromatic granules are water soluble and thus are not preserved in the widely used Giemsa stain [6]. However, immunohistochemistry enables detection and quantification of basophils either using antibodies against basophil-specific antigens like 2D7 and BB1 or a combination of antibodies against tryptase and CD117 (KIT) since neoplastic basophils have been found to express the mast cell-related antigen tryptase but not CD117 which is otherwise constitutively expressed on mast cells [7-9]. Thus, small round tryptase-positive/CD117-negative cells can be regarded as basophils in histological sections. CD117-negative round tryptase-positive cells are either mast cells or myeloblasts while spindle-shaped tryptasepositive cells are mast cells.

Cytomorphological atypia of basophils mainly consists of hypogranulation and/or pronounced granulation defects in the cytoplasm [10]. A most intriguing finding is immature basophils with hypo- or even non-segmented (mono- or bilobed) nuclei which easily can be confused with mast cells. On the other hand, immature mast cells can easily be confused with basophils as such cells often contain bi- or polylobed sometimes monocytoid nuclei [11]. If blast-like cells with only a few metachromatic granules are detected in blood and/or bone marrow smears, these cells should be termed "metachromatic blasts" and are always indicative of a myeloid neoplasm [12]. In such cases, it is impossible by morphology alone to state whether the cells belong to the mast cell or basophil lineage. In such cases, immunophenotyping or even electron microscopy has to be performed. Abundant immunohistochemical expression of tryptase by basophils can be regarded as a sign of atypia since it is found almost exclusively in neoplastic states like chronic myeloid leukemia.
Mast cells

In contrast to basophils, the metachromatic granules of mast cells are easily recognizable in routine stainings containing basic dyes like Giemsa or toluidine blue [13]. However, hypo- or completely degranulated mast cells are hardly detectable in conventional stains due to their fibroblast-like appearance. Therefore, immunostaining with antibodies against mast cell-related antibodies like anti-tryptase or anti-CD117 should be applied in all cases of suspected mastocytosis $[14,15]$.

Cytological atypia of mast cells comprises a significant increase in spindle-shaped forms, hypogranulation of the cytoplasm and monocytoid, or bilobed appearance of nuclei. Marked nuclear atypia, in particular bi- or even polylobed nuclei, and/or a high nucleocytoplasmic ratio in mast cells is a typical finding in more advanced subtypes of mastocytosis like aggressive systemic mastocytosis or even mast cell leukemia [11]. Moreover, immunohistochemical prove of expression of CD25 enables to identify these mast cells as atypical. CD25-expressing mast cells are usually indicative of mastocytosis [16].

\section{Normal values}

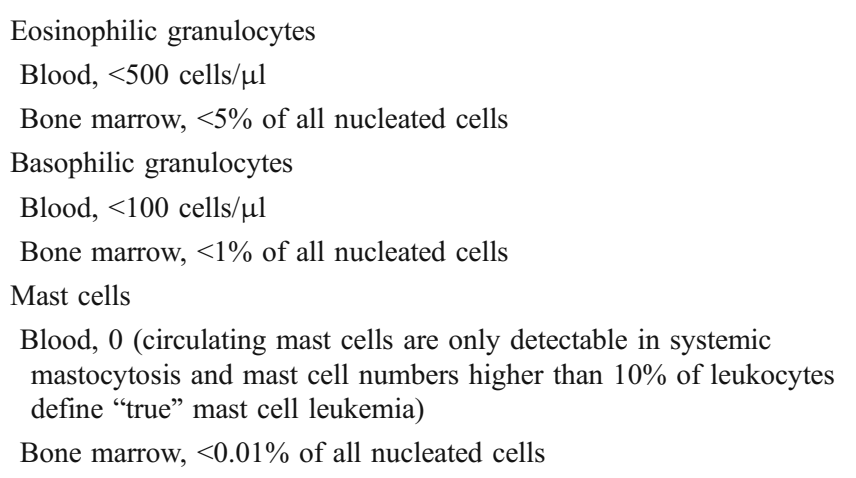

\section{Correlation of quantitative findings and grade of atypia with neoplastic myeloid disorders}

Eosinophilic granulocytes

\section{Mild eosinophilia}

Mild eosinophilia, although not well-defined, should be diagnosed when the number of circulating eosinophils exceeds $500 / \mu \mathrm{l}$ and is less than $1,500 / \mu \mathrm{l}$ (as the cutoff value for diagnosis of hypereosinophilic syndrome or neoplastic disorders like chronic eosinophilic leukemia) 
$[1,17]$. Regarding the bone marrow, a generally accepted definition for "mild eosinophilia" is lacking, but the number of eosinophils should exceed at least $5 \%$ and comprise roughly less than $20 \%$ of all nucleated cells (Table 1).

Mild eosinophilia without cytological atypia is frequently seen in reactive states and is per se not suggestive for a neoplastic hematological disorder. Mild eosinophilia is also seen frequently in patients with systemic mastocytosis especially in the bone marrow and in association with compact mast cell infiltrates [15]. In addition, mild to moderate eosinophilia without major cell atypia is frequently observed in chronic myeloid leukemia [1].

Mild eosinophilia with cytological atypia is rarely observed but might occur in myelodysplastic syndromes and in disorders defined as myelodysplastic syndromes/ myeloproliferative overlap neoplasms (MDS/MPN) according to the updated WHO classification system of hematological tumors [18].

\section{Marked eosinophilia}

Marked eosinophilia can best be defined when the number of circulating eosinophils exceeds $1,500 / \mu \mathrm{L}$ [1]. Marked eosinophilia of bone marrow is not defined yet, but more than $20 \%$ eosinophils of all nucleated cells can be regarded as marked eosinophilia.

Marked eosinophilia without cytological atypia may be seen in helminthic infections but also in allergic or

Table 1 Eosinophilia: correlation of quantitative and qualitative findings with diagnosis

\begin{tabular}{lll}
\hline Diagnosis & Increase & Atypia \\
\hline Reactive eosinophilia & + & - \\
HES & ++ & - \\
CEL, nos & ++ & + \\
MPNEo & ++ & + \\
ALL with IgH-IL3 & ++ & - \\
AMLM4Eo & $++^{\mathrm{a}}$ & + \\
CML & $+/++$ & - \\
SM & $+/++$ & - \\
SMEo & ++ & - \\
SM-AHNMD (CEL) & ++ & + \\
\hline
\end{tabular}

+ mild eosinophilia, ++ marked eosinophilia, HES hypereosinophilic syndrome, CEL, nos chronic eosinophilic leukemia, not otherwise specified, MPNEo myeloproliferative neoplasms with eosinophilia, $A M L M 4 E o$ acute myeloid leukemia with eosinophilia (inv16), CML chronic myeloid leukemia, $S M$ systemic mastocytosis, SMEo SM with marked eosinophilia, SM-CEL SM with associated CEL (in the setting of a SM-AHNMD)

${ }^{a}$ Only eosinophilia of the bone marrow anaphylactic reactions [19]. This type of eosinophilia is usually transient and therefore clearly distinguishable from hypereosinophilic syndromes defined by persistent eosinophilia and end organ damage. Rare cases of metastasizing carcinomas may also be accompanied by marked blood eosinophilia [20]. Some cases of systemic mastocytosis show marked eosinophilia leading to sometimes very difficult differential diagnostic considerations, especially when molecular-cytogenetic defects are not detected [21]. If major cytological atypia of eosinophils is missing, a myeloid neoplasm (for example, chronic eosinophilic leukemia, nos) associated with systemic mastocytosis in the setting of a SM-AHNMD is unlikely and thus favors a diagnosis of "SMEo" [22].

Marked eosinophilia with cytological atypia is seen in neoplastic states like chronic eosinophilic leukemia, nos, or myeloproliferative neoplasms with eosinophilia (MPNEo; Fig. 1). A clear-cut morphological distinction between these two neoplasms is not possible, but MPNEo often shows a significant increase in atypical spindle-shaped mast cells exhibiting an aberrant immunophenotype with expression of CD25 [3]. The presence of cytogenetic abnormalities in the platelet-derived growth factor gene (PDGFR alpha or beta chains) or, very rarely, the fibroblast growth factor-1 gene (FGFR1) defines disorders belonging to the MPNEo category and excludes chronic eosinophilic leukemia by WHO criteria, although in previous classification proposals at least FIP1L1/ PDGFRA was included as a major molecular defect of chronic eosinophilic leukemia [23]. In the extremely rare cases with association of marked eosinophilia and acute lymphoblastic leukemia (ALL), there are two differential diagnoses: (1) MPNEo with FGFR1 anomaly and (2) ALL with $t(5 ; 14)$ and IgH-IL3 fusion gene [24]. While eosinophils in FGF1MPNEo are part of the clonal neoplastic cell proliferation, eosinophilia in ALL with IgH-IL3 fusion gene apparently is reactive in nature. Marked eosinophilia with cytological atypia confined to the bone marrow (blood eosinophilia is lacking) is only seen in acute myeloid leukemia with anomalies of chromosome 16 [25]. Atypia of mostly immature appearing eosinophils in such cases is further underlined by expression of naphthol-AS-D-chloroacetate esterase which is absent from eosinophils in normal/reactive states and all the other myeloid neoplasms with eosinophilia [5].

Basophilic granulocytes

\section{Mild basophilia}

In contrast to eosinophilia, permanent basophilia can be regarded as highly suggestive for a myeloid neoplasm [10]. Mild basophilia of the blood can be diagnosed when numbers of more than 100 but less than 500 circulating basophils $\mu \mathrm{L}$ are present although the upper limit is not 


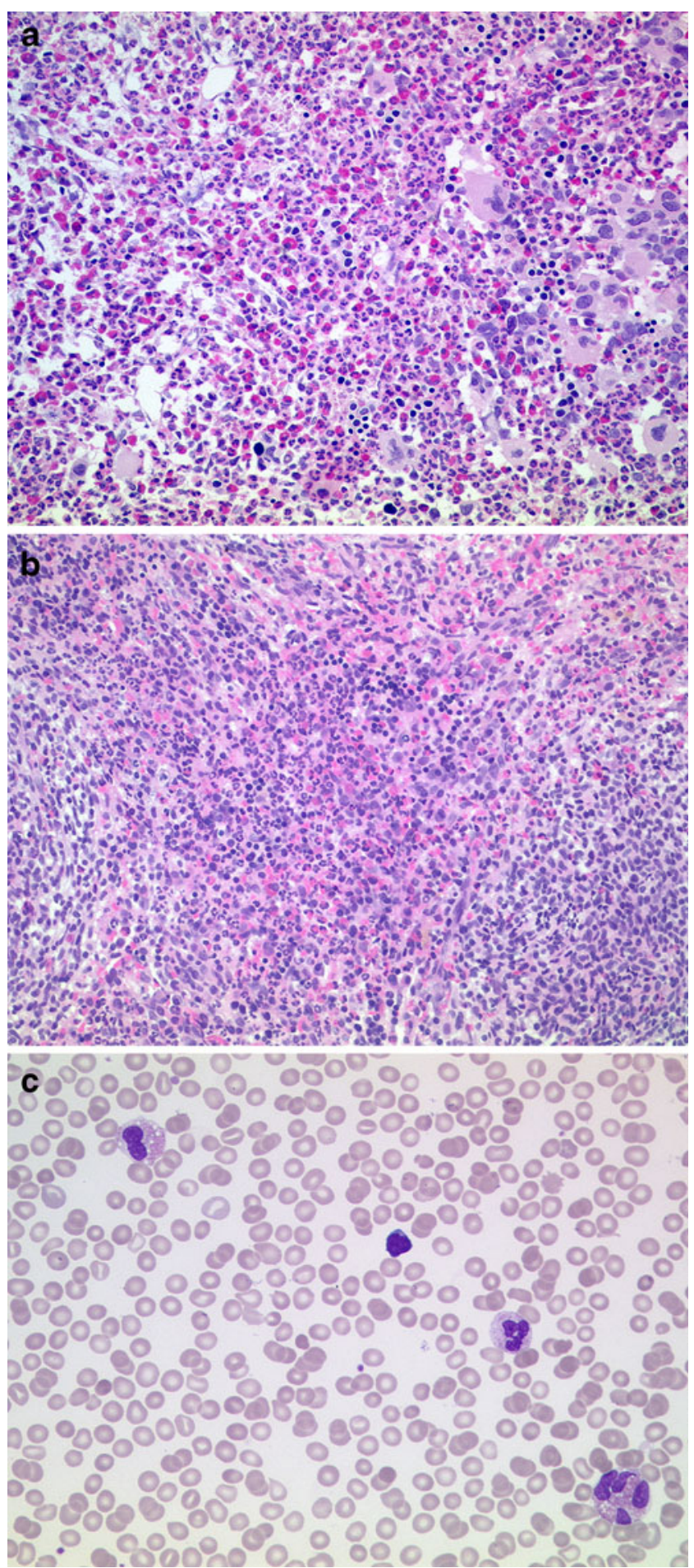

defined yet. In the normal bone marrow, the number of basophils should not exceed $1 \%$ of all nucleated cells. Difficulties may arise when atypical hypogranulated basophils have to be separated from round immature also hypogranulated mast cells or even from the so-called metachromatic blasts [11] (Table 2).

Transient or even persistent mild to even moderate basophilia may rarely occur in patients with allergic or
Fig. 1 a-c SM-AHNMD. Histology of the bone marrow exhibits both extreme hypercellularity with marked increase in mature eosinophilic granulocytes (a and $\mathbf{b} ; \mathrm{H} \& \mathrm{E}$ ) and focal compact infiltrates of mediumsized spindle-shaped mast cells (b). Note that mast cell infiltrates are not seen in a which shows grouped megakaryocytes with minor cytological atypia. Circulating eosinophils (c; Pappenheim-WrightGiemsa) exhibit major cytological atypia with hypersegmented nuclei and some giant forms. According to these findings, a mere reactive increase in eosinophils ("SMEo") seems very unlikely and an "eosinophilic" myeloid neoplasm should be diagnosed. Since molecular findings revealed an activating point mutation of KIT D816V type, a MPNEo can be nearly excluded because the presence of both KIT D816V and PDGFRalpha/beta fusion genes in one patient is extremely rare. The final diagnosis thus is SM-CEL, nos

autoimmune disorders. Otherwise, mild basophilia is observed in myelodysplastic syndromes and myeloproliferative neoplasms but with the exception of chronic myeloid leukemia is seen in a minority of the patients.

\section{Marked basophilia}

Persistent marked basophilia ( $>500$ basophils $/ \mu$ blood or $>20 \%$ of all nucleated bone marrow cells) is only seen in chronic myeloid leukemia (chronic phase and so-called basophil crisis) and the exceedingly rare chronic basophilic leukemia [26]. Bone marrow histology in such cases reveals high numbers of loosely scattered or grouped basophils detected by $2 \mathrm{D} 7, \mathrm{BB} 1$, and/or tryptase immunohistochemistry [7, 8] (Fig. 2). Basophils are small- to medium-sized round cells and therefore clearly differ from spindle-shaped tryptase-expressing mast cells which are usually present in small numbers but may form compact infiltrates in the rare occasion of an associated systemic mastocytosis (SM-AHNMD or SM-CML, respectively). Larger compact infiltrates of basophils are rarely encountered but have been described in chronic basophilic

Table 2 Basophilia: correlation of quantitative and qualitative findings with diagnosis

\begin{tabular}{lll}
\hline Diagnosis & Increase & Atypia \\
\hline Reactive basophilia? & + & - \\
MDS & + & + \\
CML & ++ & - \\
CBL & ++ & + \\
bcr-abl-negative MPN & + & - \\
SM, SMEo & - & - \\
MML & + & + \\
SM-AHNMD (CBL) & ++ & + \\
\hline
\end{tabular}

+ mild basophilia, ++ marked basophilia, MDS myelodysplastic syndrome, $C M L$ chronic myeloid leukemia, $C B L$ chronic basophilic leukemia, $S M$ systemic mastocytosis, $M M L$ myelomastocytic leukemia, $S M-C B L$ SM with associated CBL (in the setting of a SM-AHNMD; not yet described) 


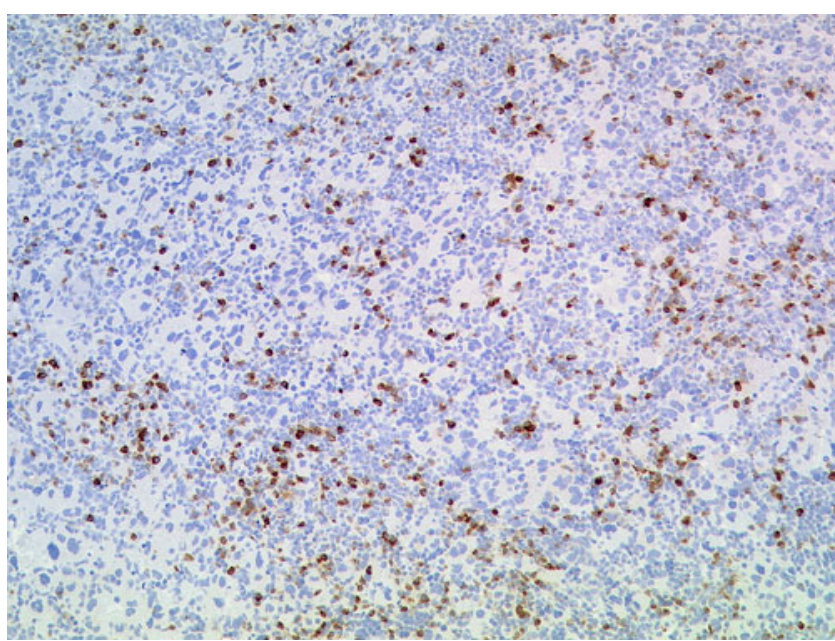

Fig. 2 Chronic myeloid leukemia. Immunostaining with anti-tryptase reveals a significant diffuse increase in small- to medium-sized cells which are basophilic granulocytes. This interpretation was confirmed by staining with anti-CD117 (not depicted), an antigen expressed by all mast cells in reactive and neoplastic states but is not found on basophils. The number of basophils is unusually high but does not qualify this case to be interpreted as "basophil crisis" of CML, especially since focal accumulations are missing. Anti-tryptase (AA1); $\mathrm{ABC}$ method

leukemia and "basophil" crisis of CML [3] (Fig. 3). Focal or even diffuse-compact bone marrow infiltrates of round tryptase-expressing cells have been termed "TROCI-bm" and always associated with a clonal hematological neoplasm. Regarding focal TROCI-bm, the spectrum of differential diagnoses comprises the rare round cell variant of a "common" KIT D816V-carrying systemic mastocytosis, the so-called well-differentiated subvariant of a CD25negative systemic mastocytosis without KIT D816V [27], chronic basophilic leukemia, and "basophil crisis" of chronic myeloid leukemia. Finding of diffuse-compact TROCI-bm includes the rare myelomastocytic and tryptase-positive acute myeloid leukemias but also chronic basophilic leukemia and high-grade variants of systemic mastocytosis like aggressive systemic mastocytosis or even mast cell leukemia [9]. Other variants of systemic mastocytosis like indolent or smoldering SM very rarely exhibit TROCI-bm.

Mast cell hyperplasia and mastocytosis

\section{Mild increase in mast cells}

A mild reactive increase in mast cells is frequently seen in tissues involved by chronic inflammatory diseases, especially in advanced or long-standing diseases with fibrosis but also detectable in a great variety of hematological neoplasms outside the setting of mastocytosis [13]. Some lymphatic neoplasms exhibit a constant diffuse reactive increase in loosely scattered round and strongly metachromatic mast cells especially lymphocytic lymphomas (chronic lymphocytic leukemia and lymphoplasmacytic lymphoma) but also hairy cell leukemia. Moreover, various myeloid neoplasms also show a mild increase in mast cells which is often reactive in nature. In a small proportion of myeloid tumors, however, an increase in spindle-shaped mast cells sometimes exhibiting an aberrant immunophenotype and expression of CD25 is detected. This is especially true for MPNEo with fusion gene anomaly of the alpha-chain of the platelet-derived growth factor [28, 29]. When compact (diagnostic) mast cell infiltrates are missing in such cases, a diagnosis of systemic mastocytosis should not be established since the activating point mutation KIT D816V is also absent in such neoplasms. Only cases with compact mast cell infiltrates and absence of KIT D $816 \mathrm{~V}$ must be categorized as an SM-AHNMD (CEL, nos, or MPNEo). However, a mild increase in loosely distributed mast cells is almost always found in the most common forms of systemic mastocytosis like indolent systemic mastocytosis which usually also exhibit disseminated compact mast cell infiltrates. Bone marrow aspirates and also histological sections often show mast cell numbers of less than $1 \%$ of all nucleated cells. The mast cells often exhibit prominent spindling, an aberrant immunophenotype with CD25 expression and KIT D816V which enables a clear-cut separation from the reactive state of a mast cell hyperplasia but not always also from clonal mast cell activation syndrome (which is a yet poorly defined disorder in which mast cells may be clonal but the criteria for a "true" mastocytosis are not fulfilled) and "occult" mastocytosis [30, 31] (Table 3).

\section{Marked increase in mast cells}

A marked increase in bone marrow mast cells is usually found in the few rare subcategories of systemic mastocytosis like smoldering, aggressive, or leukemic SM [32]. Mast cell numbers in such cases often exceed $30 \%$ of all nucleated bone marrow cells. A few cases of aggressive SM or mast cell leukemia exhibit more than $90 \%$ mast cells. The differential diagnoses here mainly focus on subtyping of SM and thorough cytomorphological investigation of blood, and bone marrow smears enable distinction between aggressive SM and (aleukemic) mast cell leukemia [3, 22] (Fig. 4). Mast cell leukemia must be diagnosed when mast cell number exceeds $20 \%$ of all nucleated bone marrow cells and/or more than $10 \%$ of leukocytes represent circulating mast cells [22]. Some exceedingly rare myeloid neoplasms with signs of mast cell differentiation but without fulfilling criteria for systemic mastocytosis have to be also considered, namely myelomastocytic leukemia and tryptase-positive acute myeloid leukemia [3]. Finally, it should be mentioned that very high numbers of mast cells 

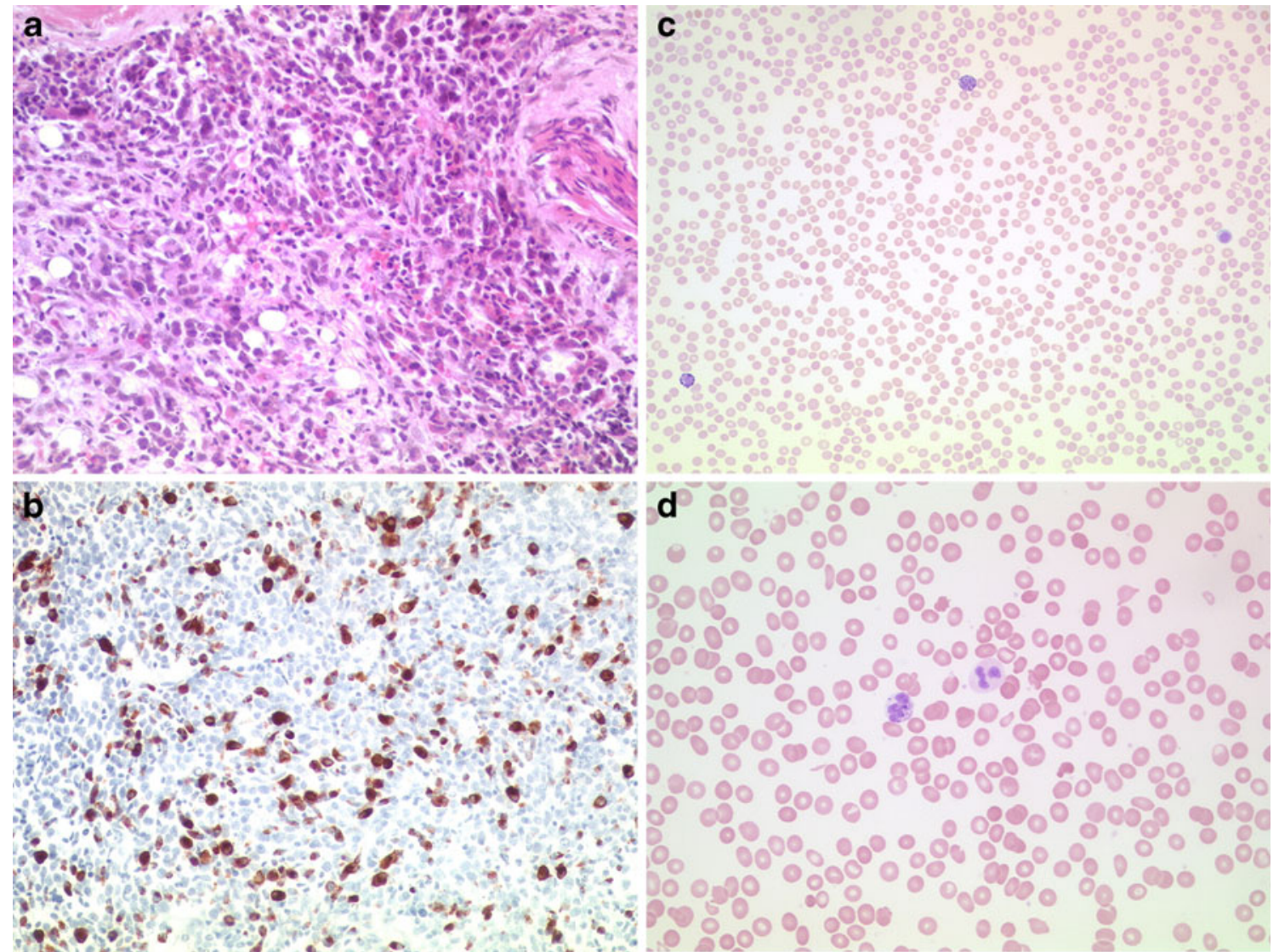

Fig. 3 a-d Chronic basophilic leukemia. This is a markedly hypercellular bone marrow with quite unusual features that do not allow a diagnosis to be established on the basis of conventional staining alone (a; $\mathrm{H} \& \mathrm{E})$. There is an increase in small- to medium-sized round lymphoid or blast-like cells, a slight increase in eosinophils, and a significant reduction of normal blood cell precursors. Immunostaining with antibody anti-2D7 shows a strong increase in pleomorphic cells which are either loosely distributed or form small groups (b; Anti-2D7; ABC

Table 3 "Mastocytosis": correlation of quantitative and qualitative findings with diagnosis

\begin{tabular}{lll}
\hline Diagnosis & Increase & Atypia \\
\hline Mast cell hyperplasia & $+/++$ & - \\
MDS & $+/++$ & $-/+$ \\
CML & $-/+$ & - \\
MPNEo & $+/++$ & $+/-$ \\
bcr-abl-negative MPN & $+/++$ & $-/+$ \\
MMCAS & $+/-$ & - \\
SM, SMEo & $+/++$ & + \\
MML & ++ & + \\
SM-AHNMD (CBL) & $+/++$ & + \\
\hline
\end{tabular}

+ mild "mastocytosis", ++ marked "mastocytosis", MDS myelodysplastic syndrome, $C M L$ chronic myeloid leukemia, $C B L$ chronic basophilic leukemia, MMCAS monoclonal mast cell activation syndrome, $S M$ systemic mastocytosis, $M M L$ myelomastocytic leukemia, $S M-C B L$ SM with associated CBL (in the setting of a SM-AHNMD; not yet described) method). Cytomorphological blood findings reveal leukopenia but a strong predominance of highly atypical often hypogranulated circulating basophils ( $>70 \%$ of leukocytes). The diagnosis of a chronic basophilic leukemia thus is confirmed immunohistochemically and cytomorphologically. The cytogenetic demonstration of BCR-ABL fusion gene abnormality qualifies this case to be interpreted either as primary BCRABL+ basophilic leukemia or secondary "basophil crisis" of CML (c and d; Pappenheim-Wright-Giemsa)

outside the group of systemic mastocytosis and related neoplasms can be seen in exceedingly rare instances termed fibromastocytic lesion or inflammatory fibroid polyps [33].

\section{Unusual myeloid neoplasms not fitting into any defined category of the WHO/FAB classification systems (crossing the boundaries of diagnosis)}

\section{Case 1}

Clinical history This is the case of a 60-year-old female patient suffering from mastocytosis with cutaneous involvement of urticaria pigmentosa adultorum type for 27 years. Systemic mastocytosis of indolent subtype was confirmed 3 years before by bone marrow histology. About 4 weeks prior to clinical admittance, the general conditioned had worsened. A tryptase level of $775 \mathrm{ng} / \mathrm{ml}$ was detected. 


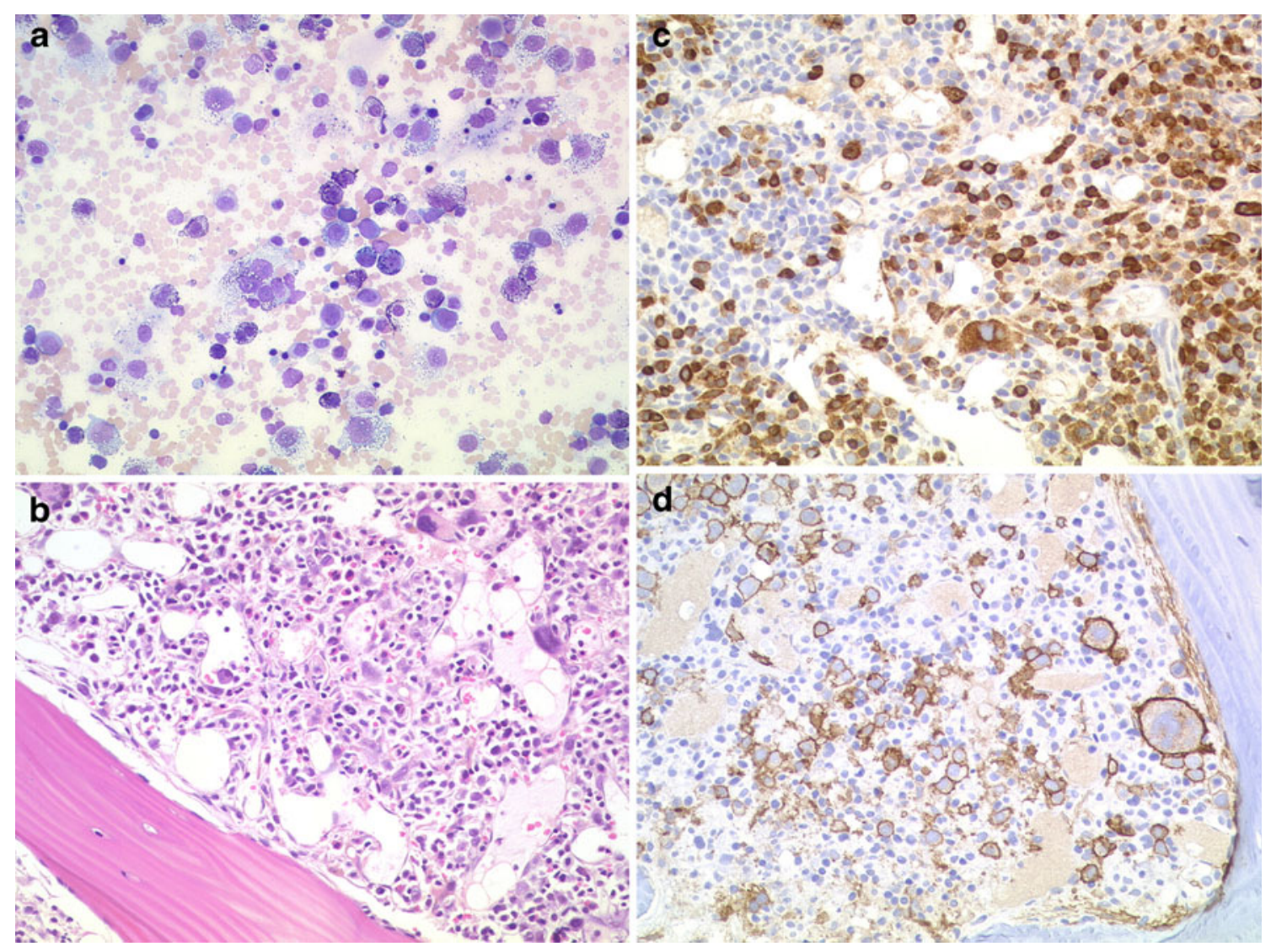

Fig. 4 a-d SM-AHNMD. Bone marrow smear with an unusual cytomorphological aspect and increase in pleomorphic often vacuolated blast cells most of them containing metachromatic granules (a) Pappenheim-Wright-Giemsa). These represent hypogranulated atypical round mast cells consisting $>50 \%$ of nucleated cells. Note a small number of non-metachromatic blast cells with moderate basophilia of the cytoplasm. Criteria of mast cell leukemia as rare subtype of systemic mastocytosis are fulfilled. Bone marrow histology is also unusual with proliferation of sinus-like vessels and marked increase in blast cells (b; H\&E). Note some atypical megakaryocytes with hyperchromatic nuclei. Immunostaining with anti-tryptase confirms the presence of a diffuse-compact infiltration by atypical mast cells. However, there is considerable number of tryptase-negative cells with blast-like features (c; Anti-tryptase (AA1); ABC method). AntiCD30 immunostaining reveals a highly aberrant phenotype of the mast cells highlighting a few giant multinucleated forms (which can easily be misinterpreted as Hodgkin's cells!). The cytogenetic demonstration of $\mathrm{t}(8 ; 21)$ enables a diagnosis of acute myeloid leukemia partially obscured by mast cell leukemia in the setting of SM-AHNMD (MCL-AML) (d; Anti-CD30 (Ber-H2); ABC method)
There were significant hepatosplenomegaly and multicentric osteolytic lesions in the skeleton, mainly involving the spine. There was pain in the right arm due to a mass lesion with a maximum diameter of $10 \mathrm{~cm}$ attached to the humerus but also deeply infiltrating the surrounding soft tissues. Molecular analysis of the blood yielded activating point mutation JAK2 V617F prompting a clinical diagnosis of accelerated phase of SM-AHNMD. Cytoreductive therapy with hydroxyurea was initiated, and shortly afterward, a core biopsy of the iliac crest and macroscopically visible parts of the mass lesion involving the right upper arm were removed (Fig. 5).

\section{Pathological findings}

1. Bone marrow: Histological investigation revealed the typical multifocal infiltration of systemic mastocytosis covering about $20 \%$ of the section area. Mast cells exhibited an aberrant immunophenotype and expressed CD25. The surrounding bone marrow was slightly edematous and hypocellular with left-shifted neutrophilic granulocytopoiesis and scattered atypical megakaryocytes.

2. Mass lesion: Histology here showed a highly cellular sarcomatous neoplasm infiltrating muscle and other soft tissues. Tumor cells were markedly pleomorphic and exhibited a round to ovoid shape. Interestingly, there was an abundance of loosely distributed multinucleated (osteoclast-like) giant cells with a tendency to form small groups. Immunohistochemistry revealed strong expression of CD99 by all the neoplastic cells. A significant proportion of cells $(20-40 \%)$ was stained by antibodies against the following antigens: CD14, 

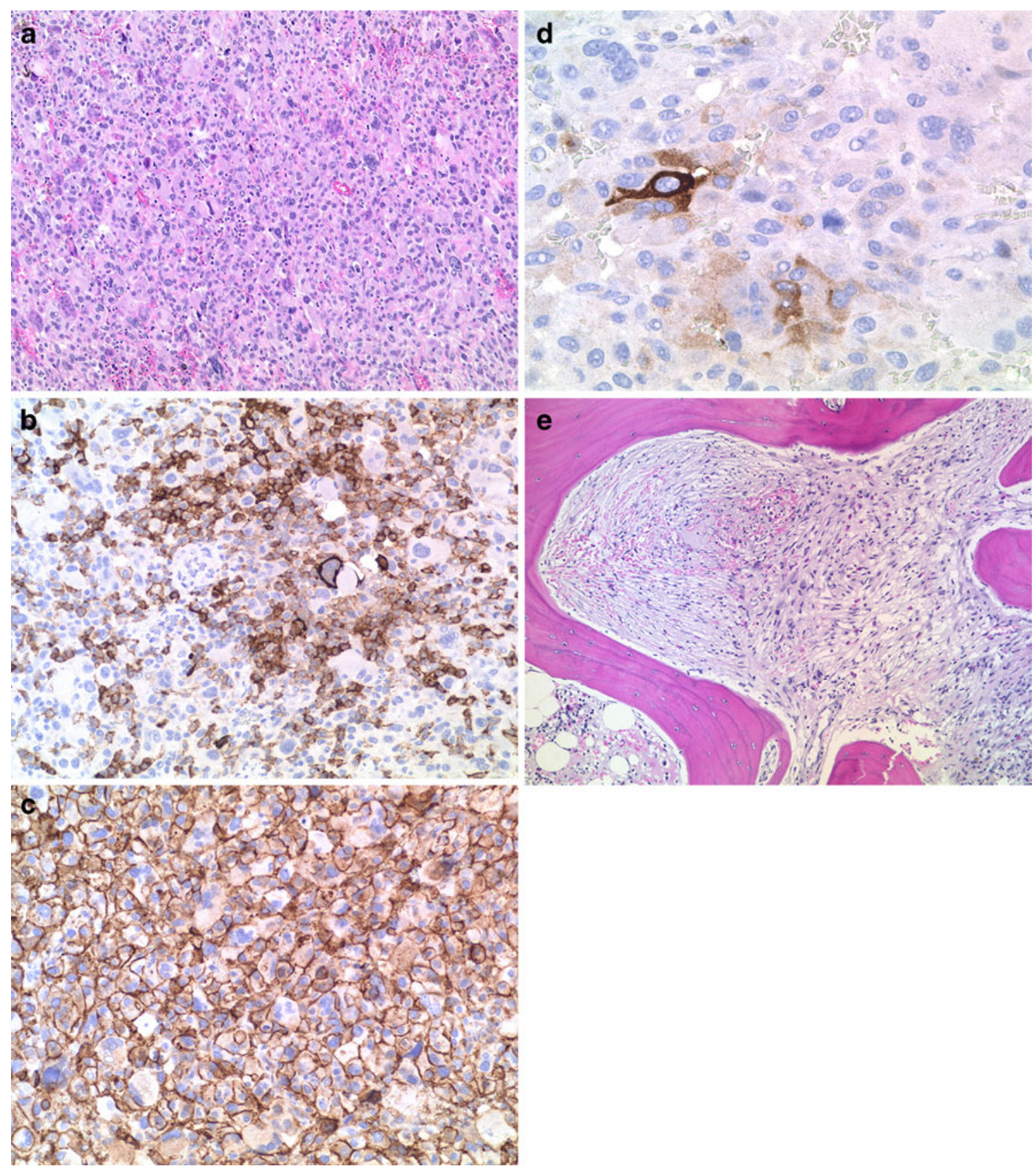

Fig. 5 a-e SM-AHNMD. Conventional staining shows a cellular neoplastic infiltrate with features of a highly anaplastic "round cell" sarcoma. Note the scattered multinucleated giant cells and the strong pleomorphism of tumor cell nuclei (a; H\&E). Immunostaining reveals some unexpected findings: a significant proportion of tumor cells express the monocyte-associated antigen CD14 (b; Anti-CD14; ABC method), all tumor express the antigen CD99 (c; Anti-CD99; ABC method), and a very small number express tryptase (d; Anti-tryptase (AA1); ABC method). Note that the large tryptase-positive cells depicted in $\mathbf{d}$ belong to the sarcomatous infiltrate. Bone marrow histology reveals the typical focal infiltrates of systemic mastocytosis consisting of packed hypogranulated spindle-shaped mast cells within a fibrous stroma (e; H\&E)
CD56, CD61, CD68, and CD117 (KIT). Coexpression of antigens CD61, CD68, and CD117 was exclusively observed by multinucleated giant cells. Only a small minority of neoplastic cells expressed the antigens myeloperoxidase and tryptase. Moreover, within the muscle, some loosely scattered spindle-shaped tryptasepositive mast cells with expression of $\mathrm{CD} 25$ were detected. 
Morphological diagnosis: systemic mastocytosis with associated JAK2 V617F+ myeloid neoplasm (SM-AHNMD) and focal transformation into a myelosarcomatous tumor exhibiting features of a secondary anaplastic mast cell sarcoma

Molecular findings Initially, activating point mutation $J A K 2 \mathrm{~V} 617 \mathrm{~F}$ was detected in the blood, but this finding could not be reconfirmed in the core biopsy of the bone marrow analyzed after cytoreductive therapy. However, a weak signal for JAK2 V617F was found in the sarcomatous neoplasm. Activating point mutation KIT D816V was found in the core biopsy of the bone marrow and, also presenting with a weak signal, in the sarcomatous tumor.

Commentary Morphological and molecular findings enable presentation of a unique case within the spectrum of mastocytosis. Firstly, there is progression of primary cutaneous disease to systemic mastocytosis combined with development of an associated myeloid neoplasm. Both tumors exhibit characteristic molecular features, thus enabling a final diagnosis of KIT D816V+ SM associated with JAK2 V617F+ AHNMD. Due to cytoreductive therapy, subtyping of the "AHNMD" was not possible based on histological findings in the core biopsy specimen. A further progression of SM-AHNMD into a sarcomatous neoplasm has never been seen before and could qualify this finding as the first case of a secondary but highly "anaplastic" mast cell sarcoma. Mast cell sarcoma itself is an extremely rare subcategory within the heterogeneous group of mastocytoses, but all cases were found to show signs of generalization and a final leukemic transformation. This behavior differs from the features of the described case. A good explanation for the weak KIT D816V signal within the sarcoma could be both the presence of only a few sarcoma cells with differentiation toward the mast cell lineage but also the presence of scattered clonal mast cells belonging to the systemic mastocytosis and corresponding very well to the morphological aspect of some spindleshaped CD25+ mast cells within intact musculature (but outside the sarcomatous infiltrate). An attractive hypothesis

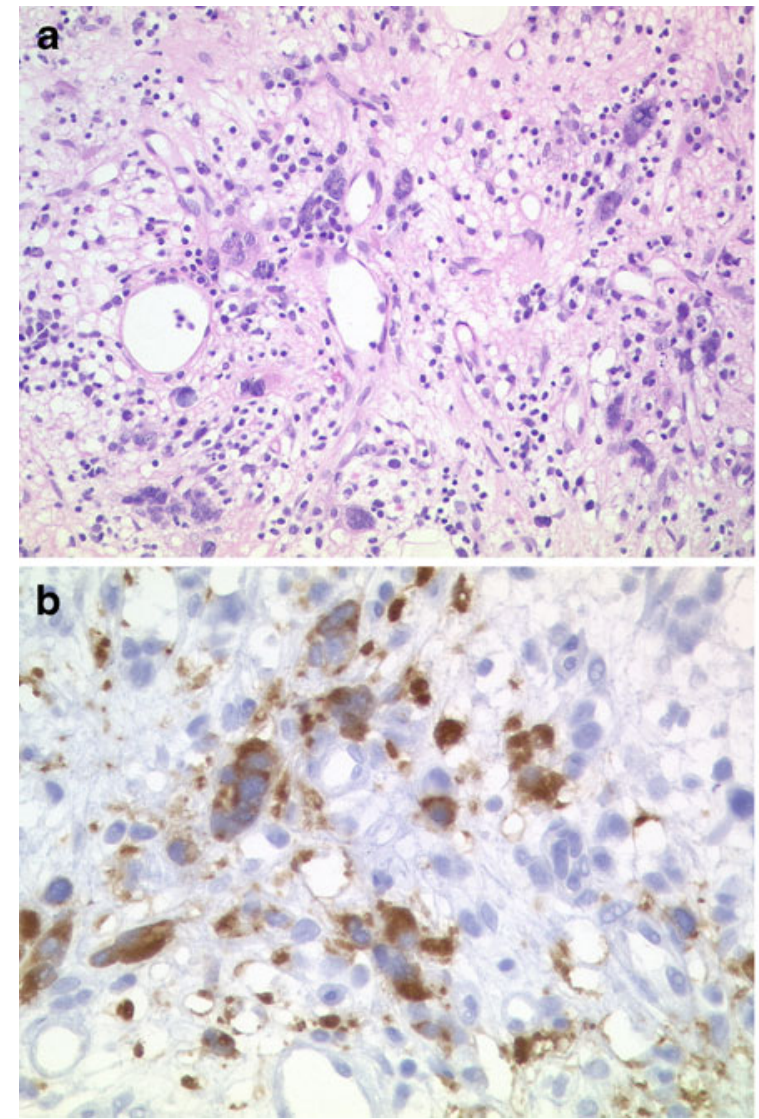

Fig. 6 a-d Acute myeloid leukemia with overlapping features of megakaryoblastic/myelomastocytic leukemia. Bone marrow histology reveals an unusual picture with an edematous stroma and focal increase in highly pleomorphic megakaryocytes (a; H\&E). Reticulin fibers were markedly increased (not depicted). There is a dominating population of small to medium-sized cells with blast-like appearance.

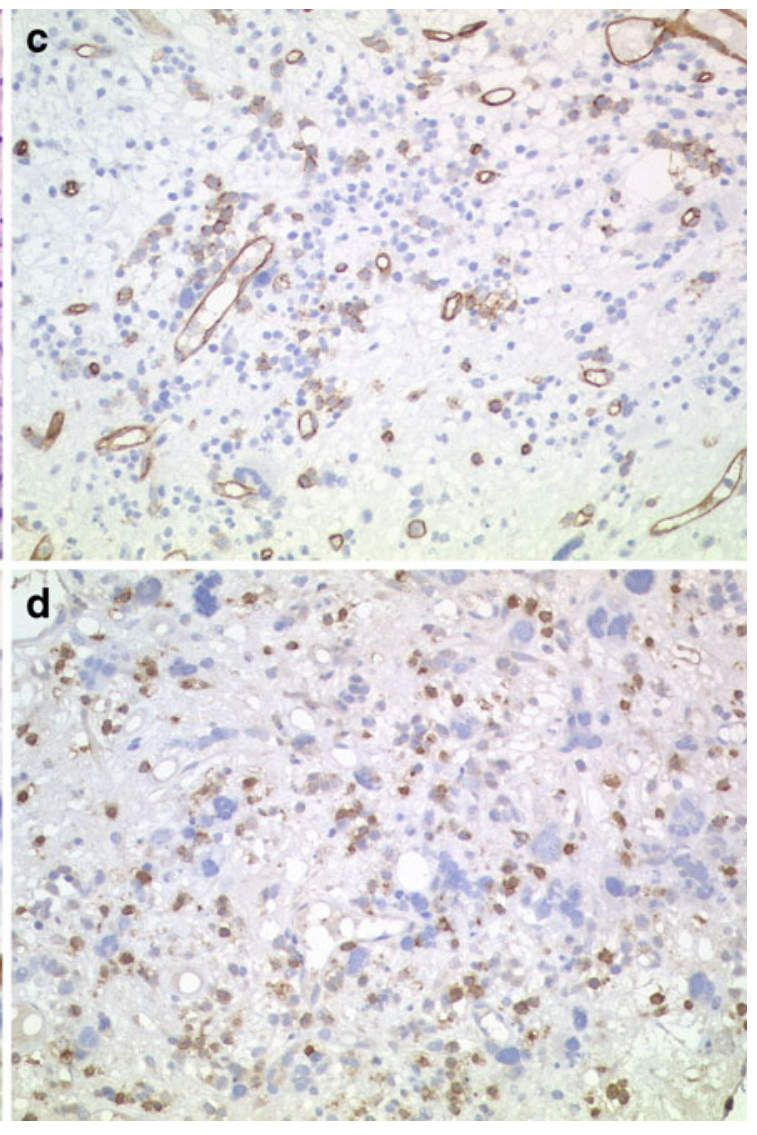

A diagnosis cannot be established on the basis of conventional histological findings. Immunostainings show a strong increase in immature often even blast-like small CD61-expressing megakaryocytes and coexpression of $\mathrm{CD} 34$ and tryptase by the blast cells (b, Anti-CD61; ABC method; c, Anti-CD34; ABC method; and d, Antitryptase (AA1); ABC method) 
would be that a more malignant AHNMD subclone developed from an immature pool of progenitors lacking $J A K 2$ and KIT mutations.

\section{Case 2}

Clinical history This is the case of a 59-year-old male patient with pancytopenia and splenomegaly. Based on the core biopsy, a diagnosis of primary myelofibrosis was established. Since the center of admittance is familiar with mastocytosis, a markedly elevated serum tryptase $(>200 \mu \mathrm{l} / \mathrm{ml})$ was detected on routine examinations but could not be explained by the bone marrow findings (Fig. 6).

Pathological findings Reevaluation of bone marrow histology yielded a complete destruction of normal microarchitecture and a markedly diffuse increase in reticulin fibers (grade 3). The picture was dominated by two findings: (1) disseminated groups and clusters of highly atypical megakaryocytes and (2) a diffuse increase in smallto medium-sized blast cells making up more than $50 \%$ of all nucleated cells. Neutrophilic granulocytopoiesis and erythropoiesis were extremely hypoplastic. Immunohistochemical analysis revealed that blasts expressed the antigens CD34, CD61, CD117, and tryptase in varying frequencies, but neither compact infiltrates of tryptaseexpressing cells nor expression of CD25 was detected. Molecular analysis showed the presence of activating point mutation JAK2 V617F, whereas KIT D816V was not found.

\section{Diagnosis: unusual JAK2 V617F-positive myeloid neoplasm with excess of blasts and marked fibrosis exhibiting overlapping features of megakaryoblastic and myelomastocytic leukemia}

Commentary The described morphological findings do not fit into diagnostic criteria for any defined myeloid neoplasm. The main differential diagnoses include systemic mastocytosis, in particular mast cell leukemia and SMAHNMD, acute panmyelosis with myelofibrosis and primary myelofibrosis while disorders within the groups of myelodysplastic syndromes, in particular refractory anemia with excess of blasts (RAEB2-F), or MDS/MPN can more easily be excluded. It is obvious that criteria for diagnosis of SM are not fulfilled since compact mast cell infiltrates, aberrant immunophenotypical characteristics of mast cells, and activating point mutation KIT D $816 \mathrm{~V}$ are lacking. Accordingly, immunophenotype of blast cells with strong expression of tryptase explains the elevated serum tryptase and thus would allow one of the following diagnoses: (a) tryptase-positive AML and (b) myelomastocytic leukemia (if metachromatic cells in the smears had reached $10 \%$ ). However, strong hypoplasia of neutrophilic cells and erythroblasts exclude both acute panmyelosis and primary myelofibrosis.

Conflict of interest The authors declare that they have no conflict of interest.

\section{References}

1. Rodig SJ, Kutok JI (2009) Bone marrow disorders with associated eosinophilia. Diagn Histopathol 15:107-115

2. Horny H-P (2009) Mastocytosis. An unusual clonal disorder of bone marrow-derived hematopoietic progenitor cells. Am J Clin Pathol 132:438-447

3. Horny H-P, Sotlar K, Valent P (2010) Differential diagnosis of systemic mastocytosis in routinely processed bone marrow biopsy specimens: a review. Pathobiology 77:169-180

4. Bain B, Gilliland DG, Vardiman JW, Horny H-P (2008) Chronic eosinophilic leukemia, not otherwise specified. In: Swerdlow S, Campo E, Harris NL, Jaffe ES, Pileri SA, Stein H, Thiele J, Vardiman JW (eds) WHO classification of tumours of haematopoietic and lymphoid tissues. IARC, Lyon

5. Leder LD (1970) Diagnostic experiences with the naphthol AS-D chloroacetate esterase reaction. Blut 21:1-8

6. Parwaresch MR, Leder LD, Dannenberg KE (1971) On the origin of human basophilic granulocytes. Acta Haematol 45:273-279

7. Agis H, Krauth MT, Böhm A, Mosberger I, Müllauer L, Simonitsch-Klupp I, Walls AF, Horny H-P, Valent P (2006) Identification of basogranulin (BB1) as a novel immunohistochemical marker of basophils in normal bone marrow and patients with myeloproliferative disorders. Am J Clin Pathol 125:273-281

8. Agis H, Krauth MT, Mosberger I, Müllauer L, Simonitsch-Klupp I, Schwartz LB, Printz D, Böhm A, Fritsch G, Horny H-P, Valent $P$ (2006) Enumeration and immunohistochemical characterisation of bone marrow basophils in myeloproliferative disorders using the basophil specific monoclonal antibody 2D7. J Clin Pathol 59:398-402

9. Horny H-P, Sotlar K, Stellmacher F, Krokowski M, Agis H, Schwartz LB, Valent P (2006) The tryptase positive compact round cell infiltrate of the bone marrow (TROCI-BM): a novel histopathological finding requiring the application of lineage specific markers. J Clin Pathol 59:298-302

10. Parwaresch MR (1976) The human blood basophil. Springer, Berlin

11. Sperr WR, Escribano L, Jordan JH, Schernthaner GH, Kundi M, Horny H-P, Valent P (2001) Morphological properties of neoplastic mast cells: delineation of stages of maturation and implication for cytological grading of mastocytosis. Leuk Res 25:529-536

12. Valent P, Samorapoompichit P, Sperr WR, Horny H-P Lechner K (2002) Myelomastocytic leukemia: myeloid neoplasm characterized by partial differentiation of mast cell-lineage cells. Hematol J 3:90-94

13. Parwaresch MR, Horny H-P, Lennert K (1979) Tissue mast cells in health and disease. Pathol Res Pract 179:439-461

14. Horny H-P, Sillaber C, Menke D, Kaiserling E, Wehrmann M, Stehberger B, Chott A, Lechner K, Lennert K, Valent P (2008) Diagnostic value of immunostaining for tryptase in patients with mastocytosis. Am J Surg Pathol 22:1132-1140

15. Horny H-P, Valent P (2001) Diagnosis of mastocytosis: general histopathological aspects, morphological criteria, and immunohistochemical findings. Leuk Res 25:543-551 
16. Sotlar K, Horny H-P, Simonitsch I, Krokowski M, Aichberger KJ, Mayerhofer M, Printz D, Fritsch G, Valent P (2004) CD25 indicates the neoplastic phenotype of mast cells: a novel immunohistochemical marker for the diagnosis of systemic mastocytosis in routinely processed bone marrow biopsy specimens. Am J Surg Pathol 28:1319-1325

17. Tefferi A, Gotlib J, Pardanani A (2010) Mypereosinophilic syndrome and clonal eosinophilia: point-of-care diagnostic algorithm and treatment update. Mayo Clin Proc 85:158-164

18. Vardiman JW, Brunning RD, Arber DA, LeBeau MM (2008) Introduction and overview of the classification of the myeloid neoplasms. In: Swerdlow S, Campo E, Harris NL, Jaffe ES, Pileri SA, Stein H, Thiele J, Vardiman JW (eds) WHO classification of tumours of haematopoietic and lymphoid tissues. IARC, Lyon

19. Arnes PR, Aloj G, Gentile F (2011) Eosinophilia and thrombosis in parasitic disease: an overview. Clin Appl Thromb Hemost $17: 33-38$

20. Abali H, Altundag MK, Engin H, Altundag OO, Türker A, Uner A, Ruacan S (2001) Hypereosinophilia and metastatic anaplastic carcinoma of unknown primary. Med Oncol 18:285-288

21. Pardanani A, Verstovsek S (2007) Hypereosinophilic syndrome, chronic eosinophilic leukemia, and mast cell disease. Cancer J 13:384-391

22. Valent P, Horny HP, Escribano L et al (2001) Diagnostic criteria and classification of mastocytosis: a consensus proposal. Leuk Res 25:603-625

23. Bain B, Gilliland DG, Horny H-P, Vardiman JW (2008) Myeloid and lymphoid neoplasms with eosinophilia and abnormalities of PDGFRA, PDGRB or FGFR1. In: Swerdlow S, Campo E, Harris NL, Jaffe ES, Pileri SA, Stein H, Thiele J, Vardiman JW (eds) WHO classification of tumours of haematopoietic and lymphoid tissues. IARC, Lyon

24. Meeker TC, Hardy D, Willman C, Hogan T, Abrams J (1990) Activation of the interleukin-3 gene by chromosome translocation in acute lymphocytic leukemia with eosinophilia. Blood 76:285-289

25. Arber DA, Brunning RD, LeBeau MM, Falini B (2008) Acute myeloid leukaemia with recurrent genetic abnormalities. In:
Swerdlow S, Campo E, Harris NL, Jaffe ES, Pileri SA, Stein H, Thiele J, Vardiman JW (eds) WHO classification of tumours of haematopoietic and lymphoid tissues. IARC, Lyon

26. Pardanani A, Morice WG, Hoyer JD, Tefferi A (2003) Chronic basophilic leukemia: a distinct clinico-pathologic entity? Eur J Haematol 71:18-22

27. Akin C, Fumo G, Yavuz AS, Lipsky PE, Neckers L, Metcalfe DD (2004) A novel form of mastocytosis associated with a transmembrane c-kit mutation and response to imatinib. Blood 103:3222-3225

28. Tefferi A, Pardanani A, Li CY (2003) Hypereosinophilic syndrome with elevated serum tryptase versus mast cell disease associated with eosinophilia: 2 distinct entities? Blood 102:30733074

29. Pardanani A, Reeder Li CY, Tefferi A (2003) Eosinophils are derived from the neoplastic clone in patients with systemic mastocytosis and eosinophilia. Leuk Res 27:883-885

30. Valent P, Akin C, Arock M, Brockow K, Butterfield JH, Carter MC, Castells M, Escribano L, Hartmann K, Lieberman P, Nedoszytko B, Orfao A, Schwartz LB, Sotlar K, Sperr WR, Triggiani M, Valenta R, Horny H-P, Metcalfe DD (2011) The definitions, criteria and global classification of mast cell disorders with special reference to mast cell activation syndromes: a consensus proposal. Int Arch Allergy Immunol (in press)

31. Bernd HW, Sotlar K, Lorenzen J, Osieka R, Fabry U, Valent P, Horny H-P (2004) Acute myeloid leukemia with $\mathrm{t}(8 ; 21)$ associated with "occult" mastocytosis. Report of an unusual case and review of the literature. J Clin Pathol 57:324-328

32. Horny HP, Akin C, Metcalfe DD, Escribano L, Bennett JM, Valent P, Bain B (2008) Mastocytosis. In: Swerdlow S, Campo E, Harris NL, Jaffe ES, Pileri SA, Stein H, Thiele J, Vardiman JW (eds) WHO classification of tumours of haematopoietic and lymphoid tissues. IARC, Lyon

33. Graefe H, Stellmacher F, Sotlar K, Wollenberg B, Gehrking E (2008) Inflammatory pseudotumor of the hypopharynx: clinical diagnosis, immunohistochemical findings and treatment of this rare disease. In Vivo 22:817-820 